\title{
A Pilot Study of the Chronology of Present Illness: Restructuring the HPI to Improve Physician Cognition and Communication
}

\author{
Laura M. Mazer, $M D, M S^{7}$, Tina Storage, $M D^{2}$, Sylvia Bereknyei, DrPH, $M S^{1,2,3}$, Jeffrey $C h i, M D^{2}$, and \\ Kelley Skeff, $M D, P h D^{2}$ \\ 'Goodman Surgical Education Center, Department of Surgery, Stanford University School of Medicine, Stanford, CA, USA; ${ }^{2}$ Department of \\ Medicine, Stanford University School of Medicine, Stanford, CA, USA; ${ }^{3}$ Research and Evaluation, Office of Medical Education, Stanford University \\ School of Medicine, Palo Alto, CA, USA.
}

BACKGROUND: Patient history-taking is an essential clinical skill, with effects on diagnostic reasoning, patient-physician relationships, and more. We evaluated the impact of using a structured, timeline-based format, the Chronology of Present Illness (CPI), to guide the initial patient interaction.

OBJECTIVE: To determine the feasibility and impact of the CPI on the patient interview, written notes, and communication with other providers.

DESIGN: Internal medicine residents used the CPI during a 2 -week night-float rotation. For the first week, residents interviewed, documented, and presented patient histories according to their normal practices. They then attended a brief educational session describing the CPI, and were asked to use this method for new patient interviews, notes, and handoffs during the second week. Night and day teams evaluated the method using retrospective prepost comparisons.

PARTICIPANTS: Twenty-two internal medicine residents in their second or third postgraduate year.

INTERVENTION: An educational dinner describing the format and potential benefits of using the CPI.

MAIN MEASURES: Retrospective pre-post surveys on the efficiency, quality, and clarity of the patient interaction, written note, and verbal handoff, as well as open-ended comments. Respondents included night-float residents, day team residents, and attending physicians.

KEY RESULTS: All night-float residents responded, reporting significant improvements in written note, verbal sign-out, assessment and plan, patient interaction, and overall efficiency $(p<0.05)$. Day team residents $(n=76)$ also reported increased clarity in verbal sign-out and written note, improved efficiency, and improved preparedness for presenting the patient $(p<0.05)$. Attending physician ratings did not differ between groups.

CONCLUSIONS: Resident ratings indicate that the CPI can improve key aspects of patient care, including the patient interview, note, and physician-physician communication. These results suggest that the method should be taught and implemented more frequently.

KEY WORDS: communication; clinical reasoning; electronic health records.

Received June 14, 2016

Revised September 21, 2016

Accepted November 8, 2016

Published online November 28, 2016
J Gen Intern Med 32(2):182-8

DOI: $10.1007 / \mathrm{s} 11606-016-3928-3$

(c) Society of General Internal Medicine 2016

\section{INTRODUCTION}

One of the first clinical skills taught in medical school is patient history-taking, a skill that directly impacts diagnosis, treatment, patient satisfaction, adherence, and overall health outcomes. ${ }^{1-3}$ The patient interview is perhaps the most common and essential clinical task a physician performs, and an effective interview must balance a variety of different purposes. Physicians work to establish rapport and build a relationship, ${ }^{4}$ while also obtaining essential medical information, ${ }^{5}$ assessing and understanding the patient, ${ }^{6}$ detecting psychosocial problems, ${ }^{7}$ and facilitating patient adherence. ${ }^{8}$

To accomplish all of these goals in a patient-centered fashion, students and house staff are frequently taught to take and write the patient history in the form of a prose narrative. Although the paragraphs of a prose narrative have merit, they can result in unstructured notes that lack clarity and comprehensiveness. A complete patient history can lead to a correct diagnosis in up to $75-80 \%$ of patients, ${ }^{9,10}$ emphasizing the need to identify tools that can improve our practice of this key clinical skill. This is especially important in light of the 2015 Institute of Medicine (IOM) report warning that diagnostic errors are an increasingly recognized source of morbidity, mortality, and healthcare costs. ${ }^{11}$ Threats to the quality and quantity of data obtained from a patient history impact diagnostic ability.

The current care environment, with high patient volumes, increased handoffs, and an expectation of rapid throughput $^{12,13}$ can exacerbate the challenge of obtaining and recording an accurate history. The physician who obtains the history may not be involved in the patient's ongoing care, and handoffs to new providers require a rapid verbal synthesis of information with an interpreted diagnostic plan. This synthesis may result in dilution or compression of the raw data obtained from the patient. Consultants who are later engaged face the same challenge, receiving a synthesized version of the history that is often presented around an already established diagnosis. 
Greater time constraints, increased patient load, increased handoffs, and a need to build relationships without sacrificing data gathering are key challenges for physicians when taking and recording a patient history. The Chronology of Present Illness (CPI), previously described by one of the authors of this study (KS), provides an alternative to the traditional history of present illness (HPI) that may overcome some of these challenges. ${ }^{14,15}$ The HPI is recorded as a prose narrative, often described as a story culminating in a diagnosis. To make the information "fit" into a coherent story, students - and even experienced physicians-may ignore potentially crucial facts. ${ }^{16}$ The CPI, in contrast, documents the chronological evolution of the patient's symptoms without omissions. Dates or times are placed on the left side of the page, and the descriptions of symptoms, patient activities, treatments, or other events are listed on the right side (Fig. 2). The CPI emphasizes the timeline as an overarching conceptual framework to facilitate history-taking, note-writing, case analysis, and physician-physician communication. ${ }^{14}$ By structuring the patient's symptoms according to their timeline, physicians can more easily concentrate on symptom evolution, avoiding the increased cognitive load necessary to extract the evolution of symptoms from a prose story.

In the current study, we introduced internal medical residents on a night-float rotation to the CPI format. We asked them to use the CPI to interview patients, write notes, and communicate to the oncoming day team. We hypothesized that the CPI would improve the clarity, efficiency, and usefulness of the patient interview and written note, resulting in improved patient-physician communication, physician-physician communication, clinical reasoning, and differential diagnosis.

\section{METHODS}

\section{Participants}

Postgraduate year (PGY) 2 and 3 internal medicine residents at Stanford University rotating on a 2-week night-float service were invited to participate. During this rotation, residents see new consults or admissions for internal medicine, cardiology, hematology, and oncology. The residents write a history and physical note, structuring the history portion in accordance with their own and their team's preferences. Night residents then verbally "hand off" the new patients to the day team residents each morning, and the day teams present the patients to the attending physician on rounds.

The Stanford Institutional Review Board (IRB) determined that this study did not meet federal regulations' definition of human subjects research and was exempt from IRB review.

\section{Intervention}

From November 14, 2015, through February 19, 2016, PGY-2 and PGY-3 residents on a night-float rotation were contacted by email at the halfway point in their rotation with an invitation to participate. Prior to this email, residents admitted patients without intervention, taking the history and writing the note according to their usual practice. At a mid-rotation educational dinner, residents were introduced to the CPI and given copies of a published article describing this method (Fig. 1). ${ }^{14}$ They were also shown comparison examples of real HPI notes rewritten in CPI format (Fig. 2). Residents were asked to use the CPI to take, write, and communicate all new patient histories for the remaining week of the night-float rotation.

\section{Data Collection}

All night-float residents were given a retrospective pre-post questionnaire $^{17,18}$ at the end of the 2-week rotation. Using a five-point Likert scale, residents rated the clarity and quality of their written note and verbal sign-out, the quality of patient interactions, and their overall efficiency before and after using the CPI. The day team residents completed a similar questionnaire (Appendix A). Attending physicians rotated for 1-week periods, and therefore were not able to provide retrospective pre-post data. This group was given only a post-CPI survey. They were unaware whether they were evaluating a control (pre-CPI) or an intervention (postCPI) week. Some of the attending physicians were rotating for multiple individual weeks during the study period, and were asked to complete more that one survey. All participants were also asked for open-ended comments regarding benefits and challenges associated with the CPI. Power calculations were performed to estimate a required sample

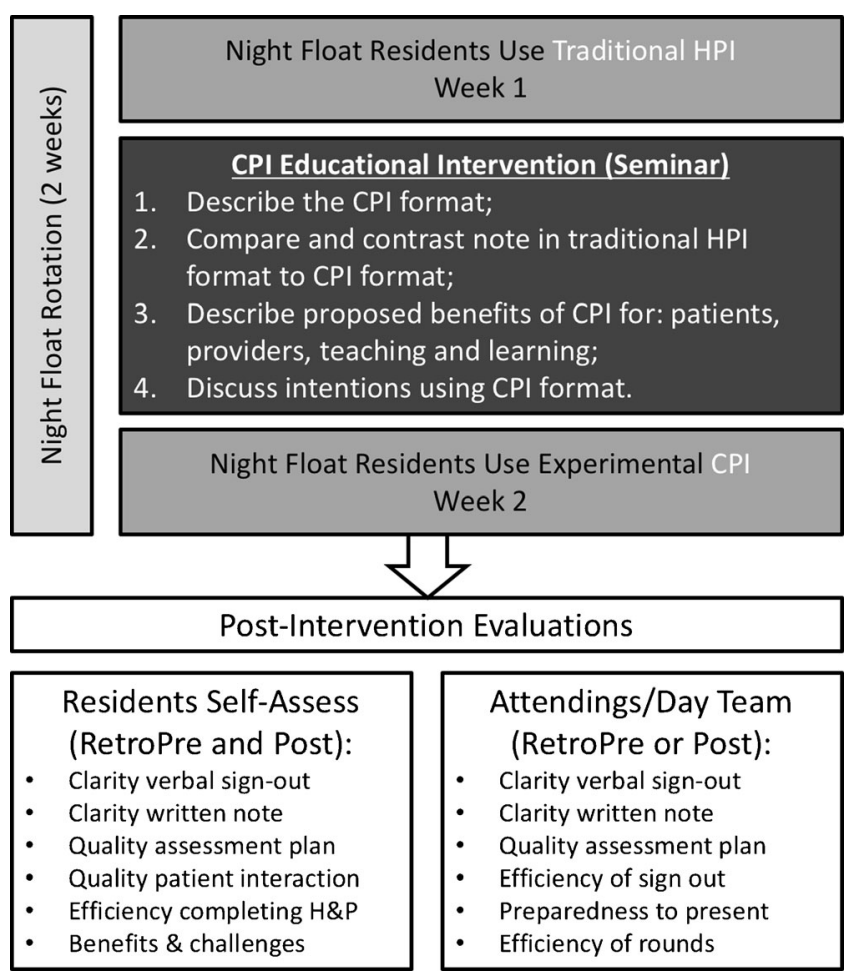

Figure 1 Study design. 


\section{HPI Example}

Patient is a 32yo M with PMH significant for anal fissures $\mathrm{s} / \mathrm{p}$ fissurectomy on $7 / 26 / 10$, now presenting with continued diarrhea with anal pain, new onset upper abdominal pain with nausea, and subjective fevers. Patient was in his usual state of health until patient travelled abroad in May 2010. He notes a change in diet, most significant for high-meat and high-EtOH, and returned with 1.5 weeks of diarrhea with minimal blood on toilet paper that self-resolved on initiation of his usual diet. He again returned overseas in June 2010 with similar dietary indiscretions, and had again the onset of diarrhea that did not resolve on his return. Two weeks later, the patient also noted significant rectal pain with defecation described as "sore and tender," He went to see his PCP on 7/13/10 after finding more blood on the toilet paper after wiping, who prescribed vicodin and Metamucil. He then saw Dr. X (GI) on 7/20/10, who started him on a 10-day course of hydrocortisone suppositories with minimal relief. He was referred to Dr. Y (colorectal surgery) on $7 / 23 / 10$ who recommended use of nitroglycerin ointment in the rectum. Dr. $Y$ then performed an exam under anesthesia on $7 / 26 / 10$, finding anterior and posterior ulcerations, with biopsy finding granulomatous tissue with granulomas and focal ulceration with lymphoid aggregates. He also performed a fissurectomy at that time. Given the patient continued to have fevers, he was started on Flagyl 250 PO BID on $8 / 3 / 10$, but on noting a "rash" of his bilateral shins, called a physician and was instructed to discontinue flagyl on $8 / 15 / 10$, without interval resolution of his skin findings. Also, of note, the patient strained his back on $8 / 12 / 10$ while getting out of a sitz bath, and had significant lumbar back pain and spasms, improved with valium $5 \mathrm{mg}$ PO BID PRN, now rated 3/10 with movement.

The patient now acutely presented to the ED with severe bilateral upper abdominal pain since 1900 on $8 / 18 / 10$ described as a "nausea" pain, that has a constant baseline level of pain with colicky exacerbations lasting 20 seconds. The patient is unable to identify any exacerbating or alleviating factors (including defecation), with the exception that lying supine helps relieve the pain. This is associated with fever to $100 \mathrm{~F}$, severe nausea, a burning sensation from the epigastrium up along the esophagus, and belching. in the ED. While in the ED, the patient was also given a GI cocktail and resulted in 1 episode of non-bloody emesis. Of note, patient states he ate a burrito with cheese and black beans several hours prior to the onset of the abdominal pain, and has not had these food in quite a while. He states a childhood history of lactose intolerance, and has recently been avoiding dairy as he feels this exacerbates his diarrhea.

Patient continues to have 4-5 loose watery stools daily, with significant pain rated $5-10 / 10$ on defecation with blood on the toilet paper and surface of the stool. He also complains of a very swollen anus causing significant discomfort and a constant "pinching" sensation of his anus rated $3 / 10$. He also notes decreased appetite, fatigue, 15 pound weight loss, and weakness over the last month. Denies sick contacts.

\section{CPI Example}

Patient is a 32yo M with PMH significant for anal fissures and diarrhea, presenting with new onset abdominal pain, nausea, and subjective fevers.

Patient was in his usual state of health until:

May 2010:

Travelled abroad, diet change (high meat and high Etoh). On return to US, had 1.5 weeks of diarrhea with blood tinged BMs, resolved with usual diet.

June 2010:

Returned overseas with same diet, noted diarrhea that did not resolve on return. Also developed rectal pain on defecation.

July 13, 2010:

Blood on toilet paper, so saw PCP. Rx: vicodin/Metamucil.

July 20: Saw GI physician, Dr. X. Rx - 10 day HC suppositories with minimal relief.

July 23: 23:

July 26: colorectal surgeon, rx nitroglycerin suppositories;

Exam under anesthesia; findings included anterior and posterior ulcerations; bx showed granulomas, focal ulceration with lymphoid aggregates. Also performed fissurectomy.

August 3, 2010:

Ongoing fevers, rx flagyl $250 \mathrm{BID}$, later rash on shins, thus, DC flagyl on $8 / 15 / 10$. Rash persisted.

\section{August 12:}

Back strain on moving from sitz bath, improved with valium.

Ongoing 4-5 loose watery stools daily, with pain on defecation, blood on the toilet paper and surface of the stool. $\mathrm{C} / \mathrm{O}$ swollen painful anus with "pinching" sensation. Decreased appetite, fatigue, 15 pound weight loss, and weakness over the last month. Denies sick contacts. Has avoided dairy because of lactose intolerance;

\section{August 18: 7PM:}

New onset severe, bilateral upper abdominal pain, constant baseline with colicky exacerbations lasting 20 seconds. Pain preceded by eating Mexican food (burrito/cheese/beans) several hours before. No exacerbating factors; relieved by lying supine. Pain associated with fever to $100 \mathrm{~F}$, severe nausea, burning sensation from epigastrium up along esophagus, belching.

Presented to ED. Pain relieved in ED by morphine and Zofran. GI cocktail -> non-bloody emesis. Admitted because of persistent symptoms and unclear diagnoses.

Figure 2 Comparison of HPI note rewritten in CPI format. Reproduced from Skeff $2014 \mathrm{~J}$ Gen Intern Med 29(1):13-15, with permission from Springer.

size based on prior data indicating that the difference in response of matched pairs with a continuous-variable Likert scale is normally distributed with standard deviation of 1.3. Detection of a true difference of one point with a power of 0.8 and a type I error of 0.05 would require 15 subjects, with each subject serving as their own matched pair. The surveys are reproduced in Appendix A.

\section{Analysis}

Average Likert ratings for the week before and after the introduction of CPI were compared using a two-tailed $t$ test $($ alpha $=0.05)$. Analyses were performed using SAS version 9.3 statistical software (SAS Institute Inc., Cary, NC, USA). Qualitative open-ended survey questions were categorized using content analysis techniques. ${ }^{19}$ Two researchers (LMM, SBM) read a subset of the comments and developed an initial coding framework in an inductive, iterative fashion, resulting in a category scheme classifying comments as positive or negative, and categorizing them in accordance with the phase of work they described (chart review, patient interview, differential diagnosis, or sign-out). This consensus coding framework was then applied to the entire dataset; after discussion of each disagreement, reviewers reached $100 \%$ consensus. A member check was completed by conducting semi-structured interviews with a subsection of surveyed residents, who reviewed the classifications and agreed with the framework.

\section{RESULTS}

\section{Participants}

Twenty-two eligible residents were assigned to a night-float rotation during the study period. During the final rotation of the study period, two residents who had previously been 
through the intervention had a second night-float block. These residents were not considered eligible and were not invited to participate during the second rotation. All 22 eligible residents (17 PGY-2, 5 PGY-3) agreed to participate. Twenty participants attended the in-person educational dinner; two were unable to attend due to family conflicts and received the information via a telephone call with one of the coinvestigators (LMM or TRS) and were sent the article electronically. Thirteen residents (59\%) had previously heard of the CPI.

\section{Survey Data}

All night-float participants completed the end-of-rotation survey (100\% response rate, $n=22$ ). On average, residents estimated that they used the CPI in $76 \%$ of patient interviews during the intervention week (range 50-100, SD 19.4). Residents reported significant improvements in the quality of patient interactions ( 3.59 vs. $4.14, p=0.001$ ), the clarity of the written note (3.32 vs. $4.41, p<0.001)$, the quality of the assessment and plan (3.72 vs. $4.05, p=0.03$ ), and the clarity of their verbal morning sign-out (3.45 vs. $4.32, p<0.001$; Table 1 ).

Day team residents also rated these elements on the same five-point scale (Table 1). In total, 134 residents received signouts from the night-float residents during the study period, among which 76 (57\%) completed the online survey. Day team ratings indicated significant improvement in the clarity of the verbal sign-out ( 3.95 vs. $4.33, p=0.003$ ) and written note (3.93 vs. $4.33, p=0.006)$. Day team residents also felt

Table 1 Opinions of Night-Float Residents, Day Team Residents, and Attending Physicians on the Week Before and After the Introduction of the CPI Method

\begin{tabular}{|c|c|c|c|}
\hline & $\begin{array}{l}\text { Before } \\
\text { CPI* }\end{array}$ & $\begin{array}{l}\text { After } \\
\text { CPI* }\end{array}$ & $\begin{array}{l}p \\
\text { value } \dagger\end{array}$ \\
\hline \multicolumn{4}{|l|}{ Night-float residents $(n=22)$} \\
\hline Clarity of verbal sign-out & 3.45 & 4.32 & $<0.001$ \\
\hline Clarity of written note & 3.32 & 4.41 & $<0.001$ \\
\hline Quality of assessment and & 3.72 & 4.05 & 0.030 \\
\hline \multicolumn{4}{|l|}{ plan } \\
\hline Quality of patient interactions & 3.59 & 4.14 & 0.001 \\
\hline Efficiency in completing the & 3.32 & 4.14 & $<0.001$ \\
\hline history and physical & & & \\
\hline \multicolumn{4}{|l|}{ Day team residents $(n=76)$} \\
\hline Clarity of verbal sign-out & 3.95 & 4.33 & 0.003 \\
\hline Clarity of written note & 3.93 & 4.33 & 0.006 \\
\hline \multirow{2}{*}{\multicolumn{4}{|c|}{ plan }} \\
\hline & & & \\
\hline Efficiency of sign-out & 3.84 & 4.24 & 0.008 \\
\hline Preparedness to present & 3.81 & 4.20 & 0.003 \\
\hline \multicolumn{4}{|l|}{ Attending physicians $(n=14)$} \\
\hline Clarity of day team & 4.06 & 4.07 & NS \\
\hline \multicolumn{4}{|l|}{ presentation } \\
\hline $\begin{array}{l}\text { Quality of written assessment } \\
\text { and plan }\end{array}$ & 4.17 & 4.21 & NS \\
\hline $\begin{array}{l}\text { and plan } \\
\text { Quality of verbal assessment }\end{array}$ & 4.00 & 4.14 & NS \\
\hline $\begin{array}{l}\text { and plan } \\
\text { Efficiency of morning rounds }\end{array}$ & 405 & 392 & NS \\
\hline & & & \\
\hline
\end{tabular}

more prepared to present the patients themselves (3.81 vs. $4.20, p=0.003)$. Of 62 attending weeks during the study period, $32(52 \%)$ attendings completed post-week surveys. The attending ratings did not indicate a significant difference, although both pre- and post-CPI ratings were generally 4.0 or above (Table 1).

\section{Open-Ended Comments}

All night-float residents were additionally asked for openended comments regarding benefits and challenges with the CPI method. Their responses related the CPI to several phases of patient care, including chart review before seeing the patient, the patient interview, developing a differential diagnosis, morning sign-out, and later interactions with consulting services (Table 2). Twenty-one participants commented on 49 perceived benefits of using the CPI, and 13 participants commented on 15 challenges. Overall, the most common challenge was the longer time commitment at each stage, including "upfront longer time commitment" and "longer conversations with patients."

Six residents also discussed specific challenges in using the CPI that eventually led to improved patient care. These challenges that led to benefits focused mostly on an increase in initial work, but with eventual payoff in clarity or efficiency. One participant wrote:

"Takes some more time initially to prepare and to decode the patient's story into a timeline but [the $\mathrm{CPI}$ saves much more time later when discussing the case."

The attending physicians were also invited to share any additional, open-ended comments. The attending comments fell into two categories. The first consisted of generally positive comments towards the CPI, for example, "I really like CPI, makes the history much easier to follow." The second category included comments on the attending physician's inability to fully evaluate resident sign-out:

"Unable to evaluate verbal component as it occurs between medical teams at 7am."

"Many attendings do not have interns do formal presentation of overnight patients."

There were no negative comments from any attending regarding the CPI.

The majority of day team resident comments (9 of 17) were general positive comments on the new method, including " $I$ love the use of the timeline!" and "Presentations and patient histories are much more concise when abandoning the traditional narrative." Of the remaining comments, three were unrelated to the format (e.g., "I prefer bedside signout for ICU patients"). The remaining five indicated that the day team did not notice a difference: "Didn't really notice a difference." 
Table 2 Representative Resident Comments on Using the CPI

\begin{tabular}{|c|c|c|c|}
\hline & Benefits & Challenges & Challenges that lead to benefits \\
\hline Pre-work & $\begin{array}{l}\text { "I found that if I drafted the CPI } \\
\text { with the information available in the } \\
\text { chart before I met the patient, it } \\
\text { helped me target my interview." } \\
(n=7)^{*}\end{array}$ & $\begin{array}{l}\text { "Up front larger time } \\
\text { commitment in filling in } \\
\text { information in the chronology." } \\
(n=2)\end{array}$ & $\begin{array}{l}\text { "Forces you to seek objective data } \\
\text { instead of perpetuating chart lore." } \\
(n=1)\end{array}$ \\
\hline Patient interaction & $\begin{array}{l}\text { "Patients were very appreciative } \\
\text { that I knew much of their history." } \\
\text { "I had one patient who was very } \\
\text { tangential and disorganized... } \\
\text { helped to organize their story to } \\
\text { what they were trying to express." } \\
(n=8)\end{array}$ & $\begin{array}{l}\text { "Longer conversation with } \\
\text { patients." } \\
\text { "Sometimes difficult to know } \\
\text { when to start the chronology (i.e. } \\
\text { patients with complicated } \\
\text { histories but here with a simple } \\
\text { complaint)." } \\
(n=8)\end{array}$ & $\begin{array}{l}\text { "Patients don't always know what } \\
\text { happened. Or get it wrong. This is } \\
\text { also a problem for the traditional } \\
\text { HPI, but at least you can hide the } \\
\text { fact that you didn't get a real history } \\
\text { when you write a traditional HPI." } \\
(n=1)\end{array}$ \\
\hline Differential diagnosis & $\begin{array}{l}\text { "Using the CPI as it turns out the } \\
\text { diarrhea started after antibiotics } \\
\text { were started for the face rash and } \\
\text { the diarrhea was from antibiotics." } \\
\text { "Greater clarity, better diagnostic } \\
\text { framework." } \\
(n=6)\end{array}$ & $\begin{array}{l}\text { "Much more time consuming } \\
\text { without significant changes in } \\
\text { assessment and plan." } \\
(n=1)\end{array}$ & $\begin{array}{l}\text { "Given it prompts you to be } \\
\text { complete, it sometimes can make } \\
\text { the history taking and } \\
\text { documentation cumbersome } \\
\text { (though, it may be worth it at the } \\
\text { end, because you feel like you } \\
\text { know the pt better)." } \\
(n=2)\end{array}$ \\
\hline $\begin{array}{l}\text { Verbal and written sign- } \\
\text { out }\end{array}$ & $\begin{array}{l}\text { "Morning sign-out is noticeably } \\
\text { more efficient with the CPI." } \\
\text { "You know exactly how you'll be } \\
\text { organizing the history before you } \\
\text { start writing it." } \\
\text { "It improved the clarity and } \\
\text { precision of written notes and } \\
\text { verbal sign-outs for patients that had } \\
\text { multiple hospitalizations." } \\
(n=24)\end{array}$ & $\begin{array}{l}\text { "Sometimes pertinent review of } \\
\text { systems info is tricky to format." } \\
\text { "Sometimes difficult to use for } \\
\text { patient transfers, given need to } \\
\text { rewrite a major portion of the } \\
\text { history... when original authors } \\
\text { have already written a } \\
\text { prose-form HPI." } \\
(n=4)\end{array}$ & $\begin{array}{l}\text { "At times, it lent itself to lengthier } \\
\text { notes (though overall, probably } \\
\text { included helpful pertinent } \\
\text { information)." } \\
(n=3)\end{array}$ \\
\hline $\begin{array}{l}\text { Impact beyond the } \\
\text { initial note or sign-out }\end{array}$ & $\begin{array}{l}\text { "Found that it was extremely } \\
\text { helpful in communicating with } \\
\text { consults. Found less time required } \\
\text { in conveying HPI during urgent } \\
\text { consults." } \\
\text { "Interns love to read the notes." } \\
(n=4)\end{array}$ & (none reported, $n=0$ ) & $\begin{array}{l}\text { "For patients with a lot of old } \\
\text { records in the chart, writing a } \\
\text { complete CPI is probably less } \\
\text { efficient (though probably more } \\
\text { helpful to providers reading the } \\
\text { note)." } \\
(n=1)\end{array}$ \\
\hline
\end{tabular}

*Refers to the number of comments in this category

\section{DISCUSSION}

This study is the first formal evaluation of the Chronology of Present Illness. As hypothesized, admitting residents reported significant improvements in all queried measures of their overnight workflow with the CPI method. Residents reported increased patient satisfaction, describing in their comments that patients felt that a CPI-oriented interview made it easier for them to tell their story, highlighting the potential to improve patient-physician communication. The day team residents also reported significant improvements in all metrics, including improved preparedness to present new patients, highlighting the method's ability to improve the quality and safety of patient handoffs. Attending physician surveys did not reflect a difference between the two methods, although openended comments reflected approval. Several attendings commented that they did not routinely supervise the sign-out process or read overnight notes, potentially indicating that the lack of significant results reflected the medical team workflow more than the impact of the CPI.

In the open-ended comments, residents reported over three times as many benefits as challenges with using the CPI. Additionally, comments indicated that although the method presented some initial challenges, it ultimately resulted in better patient care. Residents described changes to every stage of their workflow, from researching the patient's history in the medical record, through post-admission consults. There are multiple published tools and frameworks for each aspect of the initial patient interaction, from the pre-interview chart biopsy, $^{20,21}$ to the interview itself, ${ }^{4,6,7,22,23}$ to the verbal handoff ${ }^{24-}$ 27 and consult request. ${ }^{28-31}$ The open-ended comments in this study demonstrate that residents found the CPI to be a useful framework for each stage of the process, indicating that this structure can facilitate patient care through the entire patient interaction with the healthcare system.

By providing a uniform framework for obtaining and recording patient information, the CPI may reduce the cognitive load on both patients and physicians. Cognitive load theory suggests that all elements of a task, from its intrinsic complexity to the environment in which it occurs, increase the required mental effort and stress. ${ }^{25}$ Cognitive aids, on the other hand, are external resources that can simplify the work process and help users complete a task by reducing extraneous cognitive load. ${ }^{32-34}$ The CPI as a cognitive aid has the potential to benefit both patients and physicians. When the CPI is used, 
patients are encouraged to report every symptom or event, freeing them from the need to distinguish relevant from irrelevant information and providing a structure for their narrative. Several of the resident comments indicated that patients seemed to find it easier to tell their story when provided with this structure, a finding that warrants further investigation of patients' perspectives. The timeline also allows physicians to concentrate on symptom evolution instead of struggling with how to organize the data, or deciding which details to include in the initial history. In fact, this method may highlight previously unrecognized historical data that can facilitate physician learning and improved diagnosis.

This study takes on great importance now when the field of medicine is increasingly concerned with diagnostic errors. ${ }^{11,35}$ The CPI addresses several issues that can lead to diagnostic errors highlighted by the recent IOM report, including insufficient data collection and premature information integration and interpretation by care providers. The method can also improve patients' ability to describe their story by providing a structure that physicians and patients can equally understand: a timeline. By standardizing the structure of the patient's history, the CPI may enable the entire team to better understand the patient's story, a key first step in the diagnostic process.

This issue is even more relevant with the advent of the electronic medical record and the resulting "cut-and-paste" approach to notes. ${ }^{36}$ The consequences of cutting and pasting a prose note include perpetuation of chart lore, where previously misreported or inadequately recorded information is carried forward, a ballooning patient history that is the compilation of all prior notes, and eventually, the possibility that the patient history is no longer read, because it is too long or is untrustworthy. ${ }^{36,37} \mathrm{In}$ contrast, with a timeline, new providers can rapidly confirm the history's accuracy with the patient and expand the timeline with ease. The CPI can provide a continuous structure for patient information, allowing for later appreciation of symptoms whose importance may have been initially overlooked.

There are several limitations to the current study. First, this is a single-institution, single-department investigation. Our study population may not be generalizable, in part because the CPI had been taught informally to individual residents by one of the authors (KS). While no formal educational intervention has previously been undertaken, over half of the nightfloat residents had heard of the CPI. It is possible that a learning curve is required, and our positive results are due in part to pre-existing experience. Longer periods may be required for completely novice groups to see the same benefits. It is also possible that the improvement from the first to the second week of night-float represents natural improvements in efficiency with time and experience. To mitigate this possibility, we included only PGY-2 and PGY-3 residents, not interns whose learning curve is likely steeper. The participants in this study had all been through prior night-float rotations, and it is unlikely that a significant change in residents' workflow would occur independently over the study period.
This is a survey study, and has associated limitations. While we had $100 \%$ response from the night-float residents, we had lower response rates from day teams and attending physicians. This may reflect the workflow, as we did have some residents and attendings state that they did not admit any new patients during the study period and therefore did not feel qualified to answer. It is unclear what proportion of the non-respondents fall into this category. Additionally, the use of a retrospective pre-CPI rating may yield a socially desirable positive effect. While the majority of attending comments referred to the workflow, e.g., noting that they do not routinely observe sign-out, it is possible that the lack of change in attending surveys implies that the change seen in resident surveys is actually the result of social desirability bias. However, the qualitative comments lend credibility to the quantitative results, in both the resident and attending surveys. Finally, the results of this study represent the perceptions of the involved physicians. While potentially a limitation, physician perception is an important measure of the type of variables examined in this study. The self-reported improvements in efficiency and clarity are crucial first pieces of evidence for the theory that utilizing the CPI may reduce the cognitive load for the initial patient interaction.

\section{Conclusion and Next Steps}

The current approach to a narrative HPI asks providers to both record and interpret information as they take, write, and report patient history. In contrast, the CPI provides a structure for obtaining and documenting accurate patient information. Future studies should investigate the direct impact of the CPI on patient satisfaction and diagnostic reasoning skills. This first study provides compelling initial evidence that the CPI can improve the efficiency, clarity, and usefulness of the patient history, with potential benefits for provider communication, diagnostic reasoning, and patient satisfaction.

Acknowledgments: The authors would like to acknowledge the internal medicine residents at Stanford University School of Medicine. We would especially like to acknowledge the chief residents, Drs. Alexander Perino, Kate Weaver, and Evan Hall. We would also like to thank the internal medicine program director, Dr. Ronald Witteles, for his support and assistance with data collection.

Corresponding Author: Laura M. Mazer, MD, MS; Goodman Surgical Education Center, Department of SurgeryStanford University School of Medicine, 300 Pasteur Drive, H3552, Stanford, CA 94305, USA (e-mail: lmazer@stanford.edu).

Compliance with Ethical Standards:

Conflict of Interest: The authors declare that they do not have a conflict of interest.

\section{REFERENCES}

1. Lichstein PR. Chapter 3: The medical interview. In: Walker HK, Hall WD, Hurst JW, eds. Clinical Methods: The History, Physical, and Laboratory Examinations. 3rd ed. Boston: Butterworths; 1990.

2. Keifenheim KE, Teufel $\mathbf{M}, \mathbf{I p} \mathbf{J}$, et al. Teaching history taking to medical students: a systematic review. BMC Med Educ. 2015;15:159.

3. Novack DH. Therapeutic aspects of the clinical encounter. J Gen Intern Med. 1987;2:346-55. 
4. Makoul G. Essential elements of communication in medical encounters: the Kalamazoo consensus statement. Acad Med. 2001;76:390-3.

5. Beckman HB, Frankel RM. The effect of physician behavior on the collection of data. Ann Intern Med. 1984;101:692-6.

6. Bird J, Cohn-Cole S. The three-function model of the medical interview. An educational device. Adv Psychosom Med. 1990;20:65-88.

7. Rosenberg EE, Lussier MT, Beaudoin C. Lessons for clinicians from physician-patient communication literature. Arch Fam Med. 1997;6:279-83.

8. Zolnierek KB, Dimatteo MR. Physician communication and patient adherence to treatment: a meta-analysis. Med Care. 2009;47:826-34.

9. Peterson MC, Holbrook JH, Von Hales D, Smith NL, Staker LV. Contributions of the history, physical examination, and laboratory investigation in making medical diagnoses. West J Med. 1992;156: 163-5.

10. Hampton JR, Harrison MJ, Mitchell JR, Prichard JS, Seymour C. Relative contributions of history-taking, physical examination, and laboratory investigation to diagnosis and management of medical outpatients. Br Med J. 1975;2:486-9.

11. National Academies of Sciences, Engineering, and Medicine. 2015. Improving diagnosis in health care. Washington, DC: National Academies Press.

12. Bursch B, Beezy J, Shaw R. Emergency department satisfaction: what matters most? Ann Emerg Med. 1993;22:586-91.

13. Schneider SM, Gallery ME, Schafermeyer R, Zwemer FL. Emergency department crowding: a point in time. Ann Emerg Med. 2003;42:167-72.

14. Skeff KM. Reassessing the HPI: the Chronology of Present Illness (CPI). J Gen Intern Med. 2014;29:13-5.

15. Skeff KM. Restructuring the Patient's History: Enhancing the Consultant's Role as a Teacher. Gastroenterology. 2014;147:1208-11.

16. Croskerry P. The importance of cognitive errors in diagnosis and strategies to minimize them. Acad Med. 2003;78:775-80.

17. What's the difference?: "Post then pre" \& "pre then post". Cornell University Cooperative Extension, 2006. Available at: https://www. human.cornell.edu/pam/outreach/parenting/parents/upload/What-s20the-20Difference-20Post-20then-20Pre-20and-20Pre-20then-20Post. pdf. Accessed October 25, 2016

18. Skeff KM, Stratos GA, Bergen MR. Evaluation of a medical faculty development program: A comparison of traditional pre/post and retrospective pre/post self-assessment ratings. Eval Health Prof. 1992;15:350-6.

19. Elo S, Kyngas H. The qualitative content analysis process. J Adv Nurs. 2008;62:107-15.

20. Hilligoss $\mathbf{B}$, Zheng $\mathbf{K}$. Chart biopsy: an emerging medical practice enabled by electronic health records and its impacts on emergency department-inpatient admission handoffs. J Am Med Inform Assoc. 2013;20:260-7.
21. Hilligoss B. Dissecting the pre-handoff chart biopsy: Information seeking in the electronic health record. Proc Am Soc Information Sci Technol. 2010;47:1-10.

22. Redelmeier DA, Schull MJ, Hux JE, Tu JV, Ferris LE. Problems for clinical judgement: 1. Eliciting an insightful history of present illness. Cana Med Assoc J. 2001; 164:647-51.

23. Rahman A, Tasnim S. Twelve tips for better communication with patients during history-taking. ScientificWorldJournal. 2007;7:519-24.

24. Ridyard E, Street E. Evaluating the Quality of Medical Documentation at a University Teaching Hospital. BMJ Qual Improv Rep 2015;4.

25. Young JQ, Ten Cate O, O'Sullivan PS, Irby DM. Unpacking the Complexity of Patient Handoffs Through the Lens of Cognitive Load Theory. Teach Learning Med. 2016;28:88-96.

26. Solet DJ, Norvell JM, Rutan GH, Frankel RM. Lost in translation: challenges and opportunities in physician-to-physician communication during patient handoffs. Acad Med. 2005;80:1094-9.

27. Arora VM, Johnson JK, Meltzer DO, Humphrey HJ. A theoretical framework and competency-based approach to improving handoffs. Qual Saf Health Care. 2008; 17:11-4.

28. Podolsky A, Stern DT, Peccoralo L. The Courteous Consult: A CONSULT Card and Training to Improve Resident Consults. J Grad Med Educ. 2015;7:113-7.

29. Goldman L, Lee T, Rudd P. Ten commandments for effective consultations. Arch Intern Med. 1983;143:1753-5.

30. Kessler CS, Chan T, Loeb JM, Malka ST. I'm clear, you're clear, we're all clear: improving consultation communication skills in undergraduate medical education. Acad Med. 2013;88:753-8.

31. Kessler CS, Afshar Y, Sardar G, Yudkowsky R, Ankel F, Schwartz A. A prospective, randomized, controlled study demonstrating a novel, effective model of transfer of care between physicians: the $5 \mathrm{Cs}$ of consultation. Acad Emerg Med. 2012;19:968-74.

32. Rosenthal TL, Downs A. Cognitive aids in teaching and treating. Adv Behav Res Ther. 1985;7:1-53.

33. Neily J, DeRosier JM, Mills PD, Bishop MJ, Weeks WB, Bagian JP. Awareness and use of a cognitive aid for anesthesiology. Jt Comm J Qual Patient Saf. 2007;33:502-11.

34. Marshall S. The use of cognitive aids during emergencies in anesthesia: a review of the literature. Anesth Analg. 2013;117:1162-71.

35. Wen L, Kosowsky J. When doctors don't listen: How to avoid misdiagnoses and unnecessary tests. New York: St. Martin's Press; 2013.

36. Hartzband $\mathbf{P}$, Groopman J. Off the record-avoiding the pitfalls of going electronic. N Engl J Med. 2008;358:1656-8.

37. Thielke S, Hammond $\mathbf{K}$, Helbig S. Copying and pasting of examinations within the electronic medical record. Int J Med Inform. 2007;76(Suppl 1):S122-8. 